\title{
Technologies of Contraception and Abortion
}

Jesse Olszynko-Gryn

Chapter 36 in Nick Hopwood, Rebecca Flemming and Lauren Kassell (eds.), Reproduction: Antiquity to the Present Day (Cambridge: Cambridge University Press, 2018).

Soon to turn 60 , the oral contraceptive pill still dominates histories of technology in the 'sexual revolution' and after. 'The pill' was revolutionary for many, though by no means all women in the West, but there have always been alternatives and looking globally yields a different picture. $^{2}$ The condom, intra-uterine device (IUD), surgical sterilization (male and female) and abortion were all transformed in the twentieth century, some more than once. Today, female sterilization (tubal ligation) and IUDs are the world's most commonly used technologies of contraception. The pill is in third place, followed closely by the condom. Long-acting hormonal injections are most frequently used in parts of Africa, male sterilization by vasectomy is unusually prevalent in Britain, and some one in five pregnancies worldwide end in induced abortion. Though contraceptive use has generally increased in recent decades, the disparity between rich and poor countries is striking: the former tend to use condoms and pills, the latter sterilization and IUDs. ${ }^{3}$

\footnotetext{
${ }^{1}$ Heather Prescott, 'The pill at fifty: Scientific commemoration and the politics of American memory', Technology and Culture 54 (2013), 735-45.

${ }^{2}$ David Edgerton, The Shock of the Old: Technology and Global History since 1900 (London, 2006).

${ }^{3}$ Jacqueline E. Darroch, ‘Trends in contraceptive use', Contraception 87 (2013), 259-63.
} 
Contraception, a term dating from the late nineteenth century and since then often conflated with abortion, has existed in many forms, and techniques have changed and proliferated over time. Diverse local cultures have embraced new technologies while maintaining older practices. Focusing on Britain and the US, with excursions to India, China and France, this chapter will show how the patterns observed today were established and stabilized, often despite persistent criticism and reform efforts. By examining past innovation, and the distribution and use of a variety of tools and techniques, it will reconsider some widely held assumptions about what counts as revolutionary and for whom. Analytically, it will take up and reflect on one of the main issues raised by feminists and social historians: the agency of users as patients and consumers faced with choice and coercion. ${ }^{4}$ By examining practices of contraception alongside those of abortion, it will revisit the knotty question of technology in the sexual revolution and the related themes of medical, legal, religious and political forms of control. ${ }^{5}$

\section{Supply and demand}

Respectable women in Victorian Britain projected a culture of modesty and sexual innocence, ${ }^{6}$ but techniques of self-discipline depended on reproductive knowledge and constituted technologies in their own right. Some called for domestic tools such as a calendar

\footnotetext{
${ }^{4}$ For example, Linda Gordon, Woman's Body, Woman's Right: A Social History of Birth Control in America (New York, 1976); Johanna Schoen, Choice and Coercion: Birth Control, Sterilization, and Abortion in Public Health and Welfare (Chapel Hill, NC, 2005).

${ }^{5}$ On movements: Chapter 30; and on the law, Chapter 42, this volume.

${ }^{6}$ Chapter 33, this volume.
} 
or thermometer, others for a visit to the herbalist or chemist. ${ }^{7}$ In the absence of pregnancy testing, the first trimester was an uncertain time for many women and their physicians. ${ }^{8}$ Though in past centuries women took emmenagogues more to promote conception than to remove an unwanted pregnancy, by the late 1800s many thousands of women every year were using widely advertised 'female pills' as abortifacients (fig. 36.1). ${ }^{9}$ Other common methods of inducing miscarriage included falling down the stairs, drinking gin or pennyroyal tea, dilating the cervix with slippery elm bark and ingesting lead, ergot or quinine; few had access to surgical abortions. ${ }^{10}$ Statistics do not exist for earlier decades, but estimates based on official inquiries from the 1930s range from 60,000 to 125,000 abortions a year for England and Wales even though the practice had been outlawed in the nineteenth century. ${ }^{11}$ [[Figure 36.1 about here, full page.]]

\footnotetext{
${ }^{7}$ On calendars: Exhibits xii and xxix, this volume.

${ }^{8}$ Exhibit xxx, this volume.

${ }^{9}$ Jennifer Evans, “'Gentle purges corrected with hot spices, whether they work or not, do vehemently provoke venery": Menstrual provocation and procreation in early modern England', Social History of Medicine 25 (2012), 2-19; Jeffrey Weeks, Sex, Politics and Society: The Regulation of Sexuality since 1800, 3rd ed. (Harlow, 2012), pp. 87-8.

${ }^{10}$ Barbara Brookes, Abortion in England, 1900-1967 (London, 1988); Leslie J. Reagan, When Abortion Was a Crime: Women, Medicine, and Law in the United States, 1867-1973 (Berkeley, 1997); Cornelie Usborne, Cultures of Abortion in Weimar Germany (New York, 2007).

${ }^{11}$ Simon Szreter, Fertility, Class and Gender in Britain, 1860-1940 (Cambridge, 1996), p. 428.
} 
As birth control campaigners complained, many working-class women regulated fertility around menstruation more than intercourse and did not distinguish (illegal) abortion from (increasingly tolerated) contraception. Although in the interwar years networks of clinics on both sides of the Atlantic promoted prescription-only female barrier methods (cervical caps, diaphragms and pessaries), women continued to view menstrual regulation as 'natural', but birth control as 'artificial' and sinful. ${ }^{12}$ Many couples in Britain rejected 'modern' appliances as expensive and impractical, embracing instead the unreliability of 'being careful' as a means of reducing the odds of pregnancy without cheating fate or God. Viewed by some as a pleasure-enhancing sexual skill, withdrawal (coitus interruptus) was familiar, socially acceptable, easy-to-understand and conformed to the gender norm of male responsibility. Along with abstinence and the rhythm method ('Vatican roulette'), withdrawal could also be aligned with Catholicism's vague injunction to self-control. ${ }^{13}$

It was not the medically approved devices pushed by campaigners, but those pedalled by entrepreneurial vendors that found the largest share of the market. Men of all classes used 'skins' made from animal guts and, from the 1840 s, sheaths of vulcanized rubber. The industrial mass production of thinner, more comfortable and disposable latex condoms was a

${ }^{12}$ Chapter 30, this volume; Atina Grossmann, Reforming Sex: The German Movement for Birth Control and Abortion Reform, 1920-1950 (Oxford, 1995); Peter Neushul, 'Marie C. Stopes and the popularization of birth control technology', Technology and Culture 39 (1998), 245-72; Cathy Hajo, Birth Control on Main Street: Organizing Clinics in the United States, 1916-1939 (Urbana, IL, 2010).

${ }^{13}$ Kate Fisher, Birth Control, Sex and Marriage in Britain, 1918-1960 (Oxford, 2006); Fisher and Simon Szreter, Sex Before the Sexual Revolution: Intimate Life in England, 19181963 (Cambridge, 2010); Exhibit xxix, this volume. 
major innovation of the 1920s; by the 1930s, large rubber companies around Britain produced millions every year. Previously mainly imported from Germany, these sold openly from pubs, barbers, cinemas, dance halls, arcades, tobacconists and vending machines. Wartime campaigns against venereal disease and military contracts helped position the London Rubber Company as Britain’s dominant manufacturer. The company supplied 'Durex' to thousands of chemists in the 1940s and made 95 per cent of the hundred million condoms sold in $1968 .^{14}$

The US was also a 'nation of condoms'. Despite the federal Comstock Act passed in 1873 to prohibit the mailing or transport of contraceptive products and information, Americans had access to a lively underground trade. Avoiding the expense and inconvenience of a doctor's visit, consumers purchased vaginal jellies, foam tablets, suppositories, douches (most notoriously, the household cleaning product Lysol) and especially condoms directly from drug stores, mail-order catalogues and travelling peddlers. ${ }^{15}$ Following Margaret Sanger's arrest for opening the nation's first birth control clinic in Brooklyn in 1916, a New York judge ruled in favour of contraceptive use to prevent venereal disease (prophylaxis) only. The condom business boomed in the 1920s. Standards imposed by the Food and Drug Administration (FDA) pushed small-timers out of business, effectively centralizing production in the late 1930s. In 1950, two companies controlled half the $\$ 100$ million market. By 1958 , sales had risen to $\$ 150$ million, compared with $\$ 20$ million for

\footnotetext{
${ }^{14}$ Claire L. Jones, 'Under the covers? Commerce, contraceptives and consumers in England and Wales, 1880-1960', Social History of Medicine 29 (2016), 734-56; Exhibit xxvi, this volume; figure 33.4 depicts a vending machine.

${ }^{15}$ Andrea Tone, 'Making room for rubbers: Gender, technology, and birth control before the pill', History and Technology 18 (2002), 51-76, on 60.
} 
female contraceptives. ${ }^{16}$ This situation changed dramatically with the advent of the prescription-only pill in 1960 .

\section{Medicalization and population control}

Sanger's medical solution to overpopulation was developed in the mid-1950s with the support of wealthy philanthropist Katharine Dexter McCormick. The first commercial oral contraceptive, the pharmaceutical company Searle's Enovid, combined mestranol, an estrogen, and norethynodrel, a progestin, to inhibit female fertility. It was tested in Massachusetts and then on a much larger scale on poor, uneducated women in the US territory of Puerto Rico. ${ }^{17}$ Though abandoned by population controllers as too expensive and excessively reliant on patient compliance, 'the pill' proved unexpectedly popular with white, middle-class women, who were used to going to the doctor (fig. 36.2). In 1955, about half of the American women who used contraception reported relying on either condoms $(27 \%)$ or a diaphragm (25\%). Ten years later, 27 per cent used the pill, 18 per cent condoms and just 10 per cent a diaphragm. ${ }^{18}$ [[Figure 36.2 about here, full page.]]

The first decade of medicalized contraception coincided with the liberalization of laws and policies. Though the Comstock Act was overturned in 1936, thirty states still had statutes prohibiting or limiting the advertisement and sale of contraceptives in 1960. Five years later the Supreme Court ruled in Griswoldv. Connecticut that married couples had a right to privacy and, by extension, the right to purchase and use birth control. This judgement

\footnotetext{
${ }^{16}$ Ibid., 72.

${ }^{17}$ Lara V. Marks, Sexual Chemistry: A History of the Contraceptive Pill (New Haven, 2001).

${ }^{18}$ These surveys did not include men: Elizabeth Siegel Watkins, On the Pill: A Social History of Oral Contraceptives, 1950-1970 (Baltimore, 1998), pp. 61-2.
} 
superseded most proscriptive state laws, but Massachusetts continued to ban the distribution of contraceptives to unmarried individuals. In 1972, the Supreme Court extended the right of privacy in matters of birth control to the unmarried in the Eisenstadt v. Baird decision and reversed the last of the state laws against contraception. ${ }^{19}$

The optimism that greeted the pill faded as medical concerns mounted over potentially fatal side-effects, including thrombosis and cancer. Books such as Barbara Seaman's The Doctors' Case Against the Pill (1969) and Wisconsin Senator Gaylord Nelson's congressional hearings on the safety of the pill (1970) galvanized public debate in the US, while the UK government restricted higher dosages. ${ }^{20}$ And yet, even as its safety came into question, the pill encouraged women to become more active patients and empowered them to challenge medical authority. Said one satisfied patient in response to her physician's warnings, 'I don't care if you promise me cancer in five years, I'm staying on the pill. ${ }^{, 2}$ Frequent claims notwithstanding, ${ }^{22}$ no single technology launched a 'sexual revolution', but oral contraception, in concert with a host of social, cultural and political changes, did help make women's lives in the 1980s very different from those of their mothers in the 1950s.

${ }^{19}$ John W. Johnson, Griswold v. Connecticut: Birth Control and the Constitutional Right to Privacy (Lawrence, KA, 2005); David J. Garrow, Liberty and Sexuality: The Right to Privacy and the Making of Roe v. Wade (Berkeley, 1994); Chapter 42, this volume.

${ }^{20}$ Watkins, On the Pill; Marks, Sexual Chemistry.

${ }^{21}$ Quoted in Barbara Seaman, The Doctors' Case Against the Pill (New York, 1969), p. 15. See further Chapter 35, this volume.

${ }^{22}$ For example, Jonathan Eig, The Birth of the Pill: How Four Crusaders Reinvented Sex and Launched a Revolution (New York, 2014). 
Far from sweeping alternatives away, the pill emboldened researchers to develop new technologies, including the modern IUD. ${ }^{23}$ Though available from the early 1900 s, few doctors were willing to fit devices such as Gräfenberg's ring, made from silkworm gut and silver wire. After Israeli and Japanese clinicians reported positive results with new materials in 1959, the Population Council, an NGO created in the US in 1952 to focus on world population growth, funded numerous projects to bring these devices to market. ${ }^{24}$ As with the pill, IUDs were intended as cheap, effective contraception for poor, uneducated women in 'developing' countries, where coercive family-planning programmes inserted them routinely after childbirth and abortion. In 'the West', in contrast, middle-class, educated white women, including many of those coming off the pill, increasingly opted for the copper and plastic devices as a non-hormonal alternative (fig. 36.3). [[Figure 36.3 about here, $1 / 2$ page.]]

In the early 1970 s, however, the 'Dalkon Shield scandal' severely damaged the reputation of IUDs in the US. First marketed there and in Puerto Rico in 1971, the Dalkon Shield featured prongs, which prevented expulsion from the uterus but increased the chance of perforating the uterine wall, and a multifilament tail string, which extended into the vagina to aid removal but allegedly allowed bacteria to travel, or 'wick', into the uterus. It was withdrawn from the US market in 1974 amidst allegations of pelvic infections and other potentially fatal complications as well as hundreds of thousands of lawsuits against the manufacturer, A. H. Robins. ${ }^{25}$ Not until the early 2000s did Mirena, a Finnish innovation and

\footnotetext{
${ }^{23}$ Edgerton, Shock of the Old, p. 24.

${ }^{24}$ Chapter 43, this volume.

${ }^{25}$ Andrea Tone, Devices and Desires: A History of Contraceptives in America (New York, 2001), pp. 261-83.
} 
the first widely-available hormone-releasing IUD, reinvigorate the US market. ${ }^{26}$ Though the proportion of female contraceptors choosing long-acting reversible methods (mainly Mirena and subsequent variants) more than tripled in the US between $2002(2.4 \%)$ and $2009(8.5 \%)$, it remained lower than in Britain (11\%), France (23\%), Norway (27\%) and China (41\%), where copper devices continued to dominate the market. ${ }^{27}$

Reproductive technologists had high hopes not only for IUDs, but also for long-acting hormonal injections (Depo-Provera), implants (Norplant), vaginal rings and patches. ${ }^{28}$ Clinical trials began in 1969 in Chile; Finland was the first country to approve and market Norplant for general use in 1983. Like Mirena later, it came out of a collaboration between the Population Council and the Finnish pharmaceutical company Leiras Oy. The US became the seventeenth nation to sanction sale and use in 1990, and almost immediately the implants became embroiled in controversy over the potential coercion of poor, black women. Although no more than 2 per cent of American women of reproductive age (about a million) ever used it as their method of choice, by 1996 some 50,000 individuals had joined class-

\section{${ }^{26}$ Chikako Takeshita, The Global Biopolitics of the IUD: How Science Constructs} Contraceptive Users and Women's Bodies (Cambridge, MA, 2012), pp. 138-9, 141.

${ }^{27}$ Lawrence B. Finer, Jenna Jerman and Megan L. Kavanaugh, 'Changes in use of longacting contraceptive methods in the US, 2007-2009', Fertility and Sterility 98 (2012), 893-7. ${ }^{28}$ Elizabeth Siegel Watkins, 'From breakthrough to bust: The brief life of Norplant, the contraceptive implant', Journal of Women's History 22 (2010), 88-111; Watkins, 'The social construction of a contraceptive technology: An investigation of the meanings of Norplant', Science, Technology, and Human Values 36 (2011), 33-54; Wendy Kline, 'Bodies of evidence: Activists, patients, and the FDA regulation of Depo-Provera', Journal of Women's History 22 (2010), 64-87. 
action lawsuits against the manufacturer claiming restitution for pain and suffering. Norplant sales were discontinued in the US in 2002, but Bayer and the Bill \& Melinda Gates Foundation have made its WHO-approved successor product, Jadelle, available to millions of women worldwide through the recently launched Implant Access Program. In Brazil, personalized implants tailor-made in specialized pharmacies are today an increasingly popular upper-class contraceptive choice. ${ }^{29}$

\section{Surgical solutions}

Though even more controversial than implants and injections, sterilization and abortion are amongst the most common methods of avoiding pregnancy and childbirth in the world today. How did such divisive operations become so widespread? The answer differs for rich and poor countries. Used coercively in the first half of the twentieth century in the service of eugenics, to prevent the 'unfit' from reproducing, sterilization retained legitimacy to become the most popular form of contraception for married couples in the US by $1975 .{ }^{30}$ Not only women, but men too chose sterilization as concerns about oral contraception reframed vasectomy as a manly operation (fig. 36.4). Developed in China in 1974 and introduced to the US in 1986, 'no-scalpel' vasectomy was praised by Men's Health magazine in 1996 as a

${ }^{29}$ Emilia Sanabria, Plastic Bodies: Sex Hormones and Menstrual Suppression in Brazil (Durham, NC, 2016).

${ }^{30}$ Rebecca M. Kluchin, Fit to Be Tied: Sterilization and Reproductive Rights in America, 1950-1980 (New Brunswick, NJ, 2009), p. 1; Exhibit xxxi, this volume. 
painless procedure that spilled 'not even a single drop of blood' ${ }^{31}$ [[Figure 36.4 about here, full page.]]

Laparoscopy — a form of minimally invasive ('keyhole') surgery performed through a small incision in the female abdomen - made tubal ligation less expensive and less risky, but still more invasive and traumatic than vasectomy, by avoiding general anaesthesia and hospitalization. In the early 1970s, the US Agency for International Development (USAID) funded the development of portable outpatient technologies of female sterilization for use in makeshift 'camps'. Specialized equipment that fit in a suitcase was deployed on a massive scale in rural India, where one enthusiastic surgeon claimed to have sterilized over 250,000 women between 1979 and 1989 (fig. 36.5). Despite continual disclosures of coercion and even deaths, population control programmes have stabilized female sterilization as the world's commonest method of preventing pregnancy. In India and Puerto Rico, for example, tubal ligation is known simply as 'the operation'. ${ }^{32}$ [[Figure 36.5 about here, $3 / 4$ page.]]

Today, surgeons not only control fertility by operating on male and female bodies, but also routinely remove the contents of women's wombs. Of an estimated 205 million pregnancies worldwide in 2003, 20 per cent ended in induced abortion. The ratio of terminations to livebirths stands at 31 to 100 globally, but varies regionally; it is 1 to 5 in

${ }^{31}$ Sarah Shropshire, 'What's a guy to do? Contraceptive responsibility, confronting
masculinity, and the history of vasectomy in Canada', Canadian Bulletin of Medical History 31 (2014), 161-82, on 176.

${ }^{32}$ Jesse Olszynko-Gryn, 'Laparoscopy as a technology of population control: A use-centred history of surgical sterilization', in Heinrich Hartmann and Corinna R. Unger (eds), $A$ World of Populations: Transnational Perspectives on Demography in the Twentieth Century (New York, 2014), pp. 147-77. 
North America and 105 to 100 in Eastern Europe, a legacy of Soviet-era policies that limited access to contraception but made abortion widely available. ${ }^{33}$ From the mid-nineteenth century, licensed physicians increasingly used cervical dilators, curettes (hooked scraping tools) and other surgical instruments to perform abortions. By the early twentieth century, dilation and curettage (D\&C), which involves opening the cervix and scraping out the uterine contents, combined with asepsis, anaesthesia, analgesia and later antibiotics, had become the standard medical practice for first trimester terminations. D\&C remained dominant in the West until the early 1970s, when it was supplanted by vacuum aspiration, another Chinese innovation.

China was one of few countries in the 1950s with an active, state-sponsored 'planned birth’ programme (jihua shengyu) for researching new techniques of fertility control. ${ }^{34}$ Designed in 1958 for use in rural China, the 'negative pressure' technique involved heating a glass bottle with a match to create a vacuum in the absence of electric power. Physicians in Japan, the Soviet Union and Eastern Europe were early adopters as abortion technology travelled East to West. ${ }^{35}$ A Los Angeles gynaecologist recalled his enthusiasm on hearing about vacuum aspiration in the mid-1960s, when the profession was still dominated by men. At a national conference in Chicago, a colleague told of completing a miscarriage for a Soviet diplomat's wife in Washington, DC. As he 'began inserting the instruments to remove

${ }^{33}$ Gilda Sedgh et al., 'Legal abortion worldwide: Incidence and recent trends', International Family Planning Perspectives 33 (2007), 106-16.

${ }^{34}$ Michelle Murphy, Seizing the Means of Reproduction: Entanglements of Feminism, Health, and Technoscience (Durham, NC, 2012), p. 155.

${ }^{35}$ Tanfer Emin Tunc, 'Designs of devices: The vacuum aspirator and American abortion technology', Dynamis 28 (2008), 353-76. 
the last of the pregnancy, a Soviet doctor, who had accompanied the patient to the operating theatre for reasons of protocol, asked: “How come you don't vacuum her?" None of us had ever heard of this vacuum machine before. I couldn't wait to get my hands on one. ${ }^{, 36}$

Before long Americans constructed their own devices for domestic and overseas use. Harvey Karman, a controversial lay abortionist in Santa Monica, patented a narrow, flexible, plastic tube that removed the need for cervical dilation and electricity. Los Angeles feminist Lorraine Rothman assembled parts purchased at grocery, hardware and pet stores into the patented Del-em for do-it-yourself 'menstrual extraction'. Cheap plastic technologies made abortion affordable for the network of outpatient clinics that activists established around the country (fig. 36.6). Meanwhile, various states had relaxed their abortion laws and USAID contracted the mass production of thousands of disposable kits, based on Karman's patent, for export. ${ }^{37}$ In 1973, the landmark ruling, Roe v. Wade, decriminalized abortion nationwide, but the 1976 Helms amendment prohibited federal foreign aid from subsidizing abortion. ${ }^{38}$ NGOs continued to distribute the kits, including in the new country of Bangladesh, where the government had temporarily legalized abortion for women who had been raped during the Liberation War. ${ }^{39}$ [[Figure 36.6 about here, $1 / 2$ page.]]

Under the Reagan presidency, religious conservatives in the Republican Party successfully restricted abortion access at the state and federal levels while 'pro-life' activists

\footnotetext{
${ }^{36}$ Quoted in Cynthia Gorney, Articles of Faith: A Frontline History of the Abortion Wars (New York, 1998), p. 197.

${ }^{37}$ Murphy, Seizing the Means, pp. 150-76.

${ }^{38}$ Sneha Barot, 'Abortion restrictions in US foreign aid: The history and harms of the Helms Amendment', Guttmacher Policy Review 16, no. 3 (2013), 9-13; Chapter 42, this volume. ${ }^{39}$ Murphy, Seizing the Means, p. 168.
} 
picketed clinics and 'rescued' unborn 'babies'. Militants turned violent in the 1990s, bombing clinics and assassinating physicians. For 'pro-choice' activists, this state of siege made access to pharmaceutical alternatives more pressing than ever. ${ }^{40}$ But research had slowed down, especially in the US, where the threat of class-action lawsuits, increasing government regulation, a seemingly saturated market and greater public scrutiny dampened enthusiasm.

As the number of US companies actively researching contraception fell from nine in 1980 to just one, Ortho Pharmaceutical, in $1990,{ }^{41}$ the World Health Organization (WHO) took the lead. Beginning in the 1970s, the WHO had built an international network of laboratories to develop new forms of contraception and abortion, including controversial antifertility 'vaccines' and male methods involving synthetic hormones. ${ }^{42}$ Clinical trials on men were stymied, however, by the absence of an existing infrastructure for testing male contraceptives, low acceptance of any risk by either clinicians or study participants, and the ethical dilemma that failures would impregnate women, not the men enrolled in the trials. ${ }^{43}$

${ }^{40}$ Kristin Luker, Abortion and the Politics of Motherhood (Berkeley, 1984); Rickie Solinger (ed.), Abortion Wars: A Half Century of Struggle, 1950-2000 (Berkeley, 1998); Chapter 30, this volume.

${ }^{41}$ Heather Munro Prescott, The Morning After: A History of Emergency Contraception in the United States (New Brunswick, NJ, 2011), p. 94.

${ }^{42}$ Nelly Oudshoorn, The Male Pill: A Biography of a Technology in the Making (Durham, NC, 2003), pp. 52-68; Jessika van Kammen, 'Representing users' bodies: The gendered development of anti-fertility vaccines', Science, Technology, \& Human Values 24 (1999), $307-37$.

${ }^{43}$ Oudshoorn, Male Pill, p. 80. 
No male pill materialized, but a new generation of female pills expanded women's choices and rekindled old debates about the boundary between contraception and abortion.

\section{'Emergency' contraception and pharmaceutical abortion}

Heralded in the New York Times back in 1966 as a 'second revolution in birth control', the 'morning-after' pill was promoted by 'fathers' of 'the pill' Gregory Pincus and Min Chueh Chang as a convenient back-up, but condemned by their former collaborator, the Catholic gynaecologist John Rock, as an abortifacient. ${ }^{44}$ Less expensive than a daily regime, especially for the uninsured, the morning-after pill promised to reduce health risks at a time when the safety of oral contraception was increasingly scrutinized. In 1968 Chang predicted that a variety of 'morning-after', 'week later', 'second-thought', 'abortion', and 'night before' pills 'would be a boon for couples who wanted 100 per cent effectiveness in preventing pregnancy'. ${ }^{45}$ But FDA approval proved elusive and pharmaceutical companies had little incentive to market a potentially controversial drug intended for infrequent, 'emergency' use.

College physicians who provided the synthetic estrogen diethylstilbestrol (DES) offlabel to 'girls unprepared for the night before' were forced to look elsewhere when longerterm use for other indications was linked to a rare form of vaginal cancer in daughters of women who had taken the drug during pregnancy. Canadian gynaecologist Albert Yuzpe's method of punching out four tablets of oral contraception was authorized in the early 1980s in Britain and West Germany, but not Canada or the US, where feminists took matters into their own hands by distributing Yuzpe regimen dosages at rape crisis and student health centres. In the late 1990s, the FDA approved the Yuzpe method; a small New Jersey-based

\footnotetext{
${ }^{44}$ Prescott, Morning After, p. 7.

${ }^{45}$ Quoted ibid., p. 19.
} 
company marketed Preven, a combined estrogen and progestin pill, as 'emergency contraception'; and feminists founded their own corporation to market Plan B (two progestinonly pills taken twelve hours apart). ${ }^{46}$ In 2010 the FDA approved ellaOne (ulipristal acetate), which extended the window of use from 72 hours to 5 days and, in 2013, the Obama Administration announced it would allow over-the-counter sales of emergency contraception to girls and women of all ages.

Less ambiguous and more controversial than emergency contraception, the 'abortion pill' was first marketed in France in 1988 by Roussel-Uclaf, a company jointly owned by the French government and Hoechst, a major West German firm. Intended for use in early pregnancy (typically up to 7 weeks) in combination with a prostaglandin, currently misoprostol, that causes uterine contractions, mifepristone or RU486, as it was then called, is an antiprogestin that alters the uterine lining to disrupt the attachment of a fertilized egg. Not as simple as popping a pill, 'medical abortion' initially required three or four clinical visits: for confirmation of pregnancy, usually by ultrasound; for abortion counselling and to swallow three tablets of RU486 under medical supervision; for an injection or suppository of misoprostol and to wait in the clinic to abort; and finally for a post-abortion checkup, usually also by ultrasound. ${ }^{47}$ It was rapidly caught in America's abortion wars.

Threatened with international boycotts by US anti-abortion groups, Roussel initially suspended distribution, but then resumed under orders from the French health minister who

\footnotetext{
${ }^{46}$ Ibid., pp. 35, 101; on DES: Chapter 35, this volume.

${ }^{47}$ Adele Clarke and Theresa Montini, 'The many faces of RU486: Tales of situated knowledges and technological contestations', Science, Technology, \& Human Values 18
} (1993), 42-78. 
declared that RU486 was 'the moral property of women'. ${ }^{48}$ When George Bush's administration banned importation in 1989, American abortion-rights groups campaigned for access. On the twentieth anniversary of Roe v. Wade in 1993, the newly elected President Bill Clinton lifted the ban, by which time Britain, China and Sweden had also passed the drug. Roussel transferred the US patent to the Population Council and the FDA granted tentative approval in 1996, but no major pharmaceutical company dared claim the commercial rights for fear of reprisals. Finally Danco, a small New York company with an unlisted phone number and address, was established with the sole purpose of marketing RU486 in the US, where it debuted in September 2000 as Mifeprex. ${ }^{49}$

FDA authorization did not end the controversy, which continued when China announced that a Shanghai-based company would supply the raw compound to Danco. By then RU486 had been approved in over a dozen countries; hundreds of thousands of women in Europe and millions more in China had used it. In the US, non-surgical providers were allowed to offer the drug as long as they could 'assess the duration of pregnancy accurately' and had made back-up arrangements for a surgical provider. Unusually for a drug of which the safety was not in question, physicians were obliged to sign a 'provider's agreement' stating that they had met the above requirements and would report all adverse events to Danco. Patients too were required to sign a detailed agreement. ${ }^{50}$ Today, its use

\footnotetext{
${ }^{48}$ Quoted in Prescott, Morning After, p. 79.

${ }^{49}$ Carole Joffe and Tracy A. Weitz, 'Normalizing the exceptional: Incorporating the “abortion pill” into mainstream medicine', Social Science \& Medicine 56 (2003), 2353-66. ${ }^{50}$ Ibid.
} 
internationally remains subject to a host of restrictions that are not grounded in clinical need. ${ }^{51}$

\section{Conclusion}

The pill was a highly successful, even revolutionary drug. By 1989 it had been taken by over 75 per cent of women born in Britain between 1945 and 1959..$^{52}$ And yet, many of them surely also used other methods and stayed on the pill for variable durations. ${ }^{53}$ When the pill was first marketed in the 1960s, men and women had long practised fertility control. New hormonal and surgical methods increased women's share of responsibility and control, but male methods persisted. Health concerns about the pill inspired 'vasectomania' in the 1970s, condoms made a comeback with the global AIDS crisis of the 1980s and withdrawal was still 'a major, widespread method' in the 1990s. ${ }^{54}$ Despite the failure of the pharmaceutical industry to produce a 'male pill', men and women collaborated in homes and clinics, variously combining male and female methods, contraception and abortion, new and old technologies. Though the sexual revolution did not see the sharp break in behaviours that is sometimes imagined, heated public debates around the pill, sterilization, abortion, women's

${ }^{51}$ Sally Sheldon, 'British abortion law: Speaking from the past to govern the future', Modern Law Review 79 (2016) 283-316.

${ }^{52}$ Hera Cook, 'The English sexual revolution: Technology and social change', History Workshop Journal 59 (2005), 109-28, on 109.

${ }^{53}$ Fisher, Birth Control, p. 242.

${ }^{54}$ Deborah Rogow and Sonya Horowitz, 'Withdrawal: A review of the literature and an agenda for research', Studies in Family Planning 26 (1995), 140-53, on 149. 
health and population control engendered a mainstream culture that featured contraceptive technologies more prominently than ever. ${ }^{55}$

Though contraceptive use has generally risen, the resulting pattern has left few commentators satisfied. Today, critics complain of over-reliance on sterilization in Asia, but underuse of IUDs in the US, where half of all pregnancies are allegedly 'unplanned'. Some feminists champion oral contraception as liberatory, while others criticize doctors for pushing women to go on the pill. Vasectomy, though cheaper and safer than female sterilization, is uncommon in most countries. Self-abortion persists where legal access is limited; in the US, prominent arrests involving the off-label use of misoprostol, available as an ulcer drug, have reignited old debates. ${ }^{56}$

Corporations, states and NGOs have created and met demand for technologies of contraception and abortion from doctors, patients and consumers. This chapter has charted some of the major trajectories. While there is still much to discover, focusing on 'the' pill has clearly obscured a richer story in which not only American innovators and industrialists, but also their state-supported counterparts in China and in France played leading roles in producing today's strikingly various cultures of fertility control.

\footnotetext{
${ }^{55}$ Weeks, Sex, Politics and Society, pp. 334-5.

${ }^{56}$ Tiana Bakić Hayden, 'Private bleeding: Self-induced abortion in the twenty-first century United States', Gender Issues 28 (2011), 209-25.
} 